$$
\begin{array}{r}
F 7200619 \\
\text { (See also F7200618) } \\
\text { D75-10635 }
\end{array}
$$

\title{
The Cleveland Aircraft Fire Tests
}

\author{
JAMES J. BRENNEMAN, United Air Lines \\ CAPTAIN DONALD A. HEINE, North Central Airlines and \\ Member, Rescue and Fire Committee, \\ Air Line Pilots Association
}

On June 30 and July 1,1966 , tests were conducted to evaluate high expansion foam's ability to extend the time for which an aircraft passenger cabin environment would remain survivable during a post-crash fire. While some results tend to confirm those of similar tests, others may shed new light on the problem.

$\mathrm{T}^{\mathrm{T}}$ ${ }^{1} \mathrm{HE}$ Cleveland tests were conducted to determine if survival time in an aircraft cabin could be extended under post-crash fire conditions by using high expansion foam to completely fill the occupied portions of the cabin interior. It was believed that the high expansion foam would hold the temperature within survivable limits while controlling smoke, toric gases, and other products of combustion, thus providing a cool, breathable atmosphere for a prolonged period of tine for the occupants, pending ultimate evacuation or rescue.

A secondary objective was to determine the composition of the smoke, gases and other products of combustion or pyrolysis that may be present in a post-crash fire in which typical modern aircraft cabin materials such as vinyl, polypropylene, polyvinyl chloride, etc., and plastics are involved in the fire.

The tests were only to prove the concept, since the foam equipment used was "off the shelf" hardware, and not suitable for use as an "on board" system.

\section{THE AIRCRAFT}

Two North American AJ-2P patrol bombers were used in an all-gear-up landing configuration with the wings level. The center section (bomb bay) of each aircraft was fitted out to represent, as closely as possible, the insulation and interior of a typical commercial aircraft passenger cabin. The cabin mock-up section measured approximately $5 \mathrm{ft}$ wide, $51 / 2 \mathrm{ft}$ high, and $141 / 2 \mathrm{ft}$ long. Fibrous glass insulation (approximately 3 in. thick) with a resin binder and an aluminum-colored plastic skin was installed in the sidewalls and ceiling. Interior finish panels were vinyl-coated Dynel* fabric, fibrous glass sheet, vinyl-coated Dynel fabric bonded to sheet aluminum, and vinyl-coated fibrous glass with vinyl foam padding. The

"Trade name of the Union Carbide Corporation. 
forward and aft bulkheads of the cabin section were honeycomb panels. The forward bulkhead panels had a resin-impregnated paper core; the aft, aluminum-cored. Plastic sheets were bonded to the honeycomb panel. Twelve complete seat cushions and backs were suspended from steel wires in the cabin. Half of the cushions were latex foam, and the remainder were urethane foam. The floor was covered with carpeting composed of a polypropylene pile with a jute base and polyethylene back. The total weight of cabin materials and insulation was $2383 / 4$ lbs per airplane.

\section{INSTRUMENTATION AND TEST SETUP}

Ten thermocouples were located at floor level, seat back height, and ceiling level in the cabin mock-up section, and two, at the high point of the aircraft beneath the cockpit canopy (see Figure 1). Eight thermocouples had simple metallic tubing shields, and four were completely shielded in blackened copper spheres. All thermocouples were connected to multipoint or single-point Honeywell recorders to provide a constant temperature record throughout the test period. The thermocouple series designated TA were assigned three alternating channels each, and the thermocouple series designated TS and TR were assigned six alternating channels, each to provide closely spaced recording points:

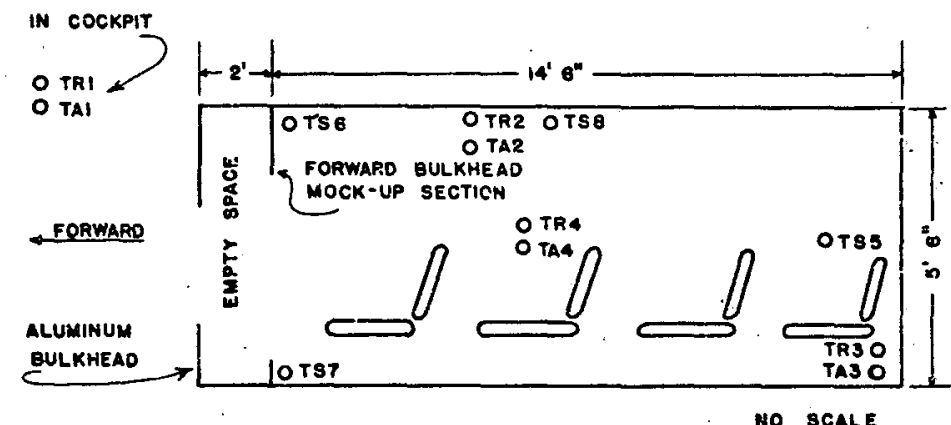

No SCALE

TRI \& TA1 - Cockpit, pilot's head

TR2 \& TA2 - Center cabin, 3 in. below ceiling, centerline

TR3 \& TA3 - Rear of cabin, 3 in. above floor, part side

TR4 \& TA4 - Center cabin, head high sitting position, centerline

755 - Center seat, 4th row, head high sitting position, centerline

TS6 - Forward bulkhead, 6 in. below ceiling, 1 ft inboard port side

TS7 - Forward bulkhend, 3 in. above floor, I ft inboard port side

IS8 - Center cabin, 2 in. below celling, centerline

Figure 1. Thermocouple locations for. Cleveland fire.tests.

It was deemed desirable to obtain data on smoke density in the cabin area as a function of time. Two detectors were used in each aircraft for this purpose. In each case, one detector was suspended about 6 in. from the ceiling, and the other about 20 in. from the ceiling: The suspension 
point in both aircraft was at the second row of seats, and on the longitudinal centerline.

Each smoke detector consisted of a light source, lens, and photocell, all mounted in a suitable frame. A shroud was provided at installation to eliminate stray or ambient light from reaching the photocells.

Calibration of these devices was accomplished with Fodak Wratten neutral density filters in 10 per cent increments, thus providing attenuation, or opacity, from zero to 90 per cent. Plots of the calibration runs for each of the two detectors for each of the two events are shown in Figures 2 and 3. Plots of the smoke density (as per cent attenuation of light) for each event are shown in Figures 4 and 5 . All of the foregoing data were recorded on a Honeywell 906. Visicorder; the detectors were powered by a Hewlett-Packard regulated power supply.

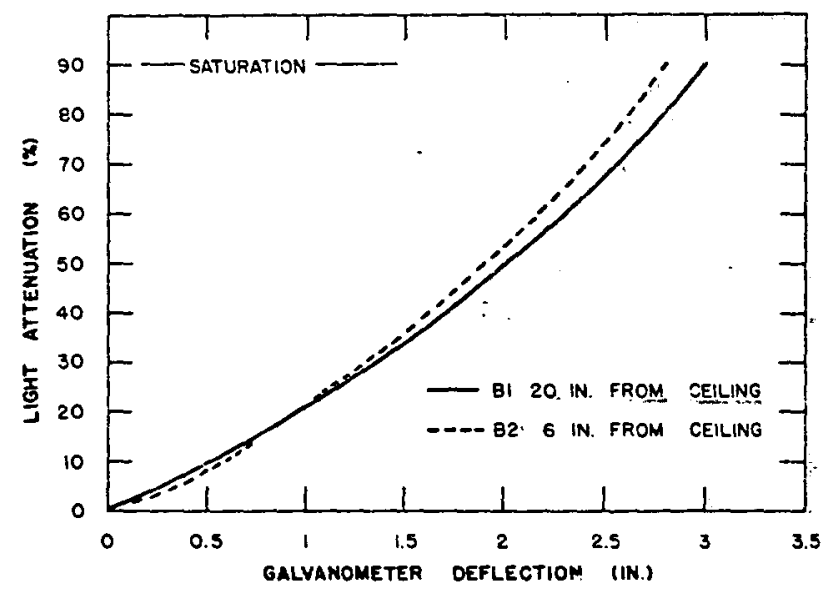

Figure 2. Smoke detector calibration curves, control aircraft.

Samples of the atmosphere during the test fires were obtained from three separate locations within the aircraft. Stainless steel and copper tubing sample leads connected to banks of 500-cc copper flasks were used. for this purpose. An electrically driven vacuum pump located down ine from the flasks provided a sample velocity through the leads calculated at 10:3 fps. Each flask was individually valved at intake and outlet to provide selectivity. Simultaneous samples from sampling locations were taken at varying intervals.

The lead designated as No. 1 was located in the cockpit of the aircraft at the approximate position of the pilot's headrest; lead No. 2 was located in the cabin mock-up section approximately $3 \mathrm{in}$. below the ceiling on the longitudinal and lateral centerlines; and lead No. 3 was located directly below lead No. 2 and at the height of the passenger seat headrest.

A 3-ft $\times 5$-ft $\times 10$-in. deep stee! pan was located immediateiy adjacent to the fuselage, the long dimension of the pan parallel to the longitudinal axis of the airplane. The pan straddled the bulkhead between the 
cabin mock-up and the vacant aft section of the fuselage. An approximately 4-in. deep water bottom was placed in each pan to provide a level base for the fuel. Two pans were positioned at each aircraft. Only the upwind pan, however, was fueled and ignited in each test.

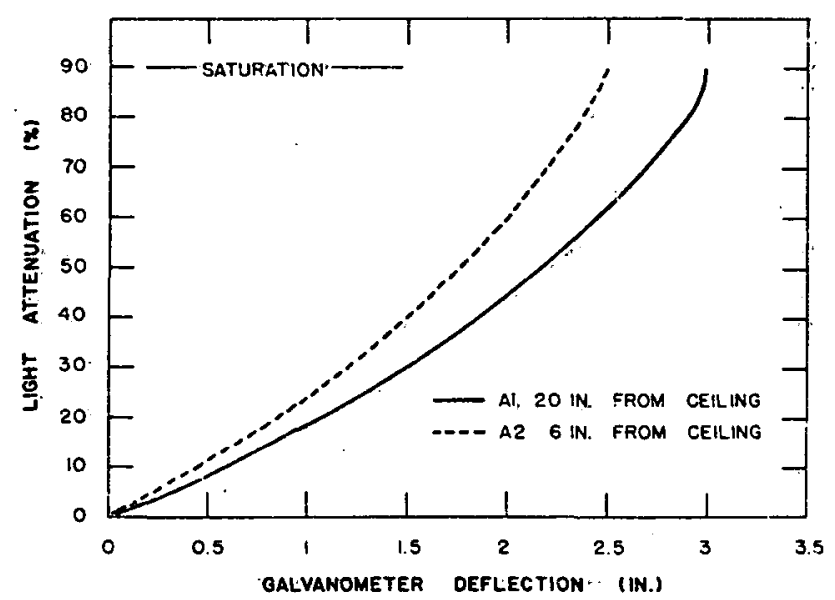

Figure 3. Smoke detector caliöration curves, test aircraft.

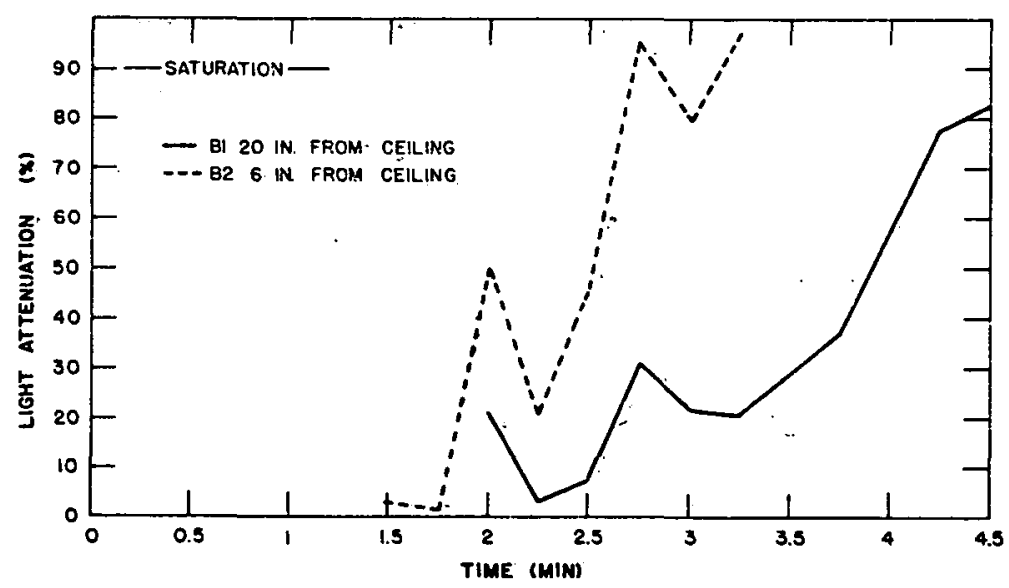

Figure 4. Smoke accumulation in control aircraft, Test 1.

Both test aircraft were void of any fuel or fuel vapor in the fuel systems. Engine oil was present in the engines but did not become involved in the fire at any time. Hydraulic systems were drained but not purged.

Except for the starboard cockpit hatch window, all openings to the test aircraft were closed for the duration of the test. The bulkhead door between the cockpit and the cabin mock-up section was secured in the open position.

All times referred to shall be construed as total elapsed time in minutes and seconds from ignition of the fuel pan. Temperatures in degrees 
Fahrenheit are those taken from the records of thermocouples located throughout the aircraft.

TEST FIRE NO. 1

The objective of Test 1 was to establish data on the burning characteristics of the aircraft without attempting to control or extinguish the fire until the test had been concluded. During this test, wind direction was variable, and wind velocity was from 0 to 3 knots.

The port pan was fieled with 20 gallons of Type $A$ (kerosene) aviation turbine fuel with a fuel depth of approximately 2 in. One-half pint of automotive gasoline was used as a primer to aid ignition of the kerosene.

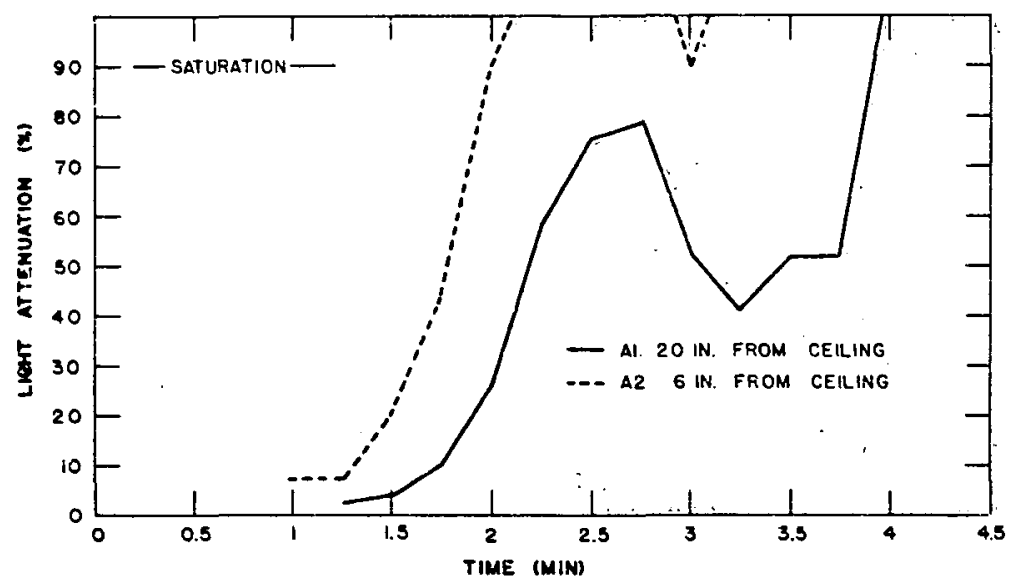

Figure 5. Smoke accumulation in test aircraft, Test.2:

The initial burn-through of the fuselage skin occurred in the area at the left rear of the mock-up section, approximately $2 \mathrm{ft}$ above the cabin floor. The skin thickness at this point was 0.035 in., and skin failure occurred $1 \mathrm{~min} 3 \mathrm{sec}$ after ignition. The first indication of smoke in the cabin was at $1 \mathrm{~min} 30 \mathrm{sec}$ (Figure 4), and the first temperature rise occurred at. $1 \mathrm{~min} 40 \mathrm{sec}$ at the cabin ceiling (Figure 6). At approximately $2 \mathrm{~min} 45 \mathrm{sec}$, the smoke detector located 6 in. from the ceiling indicated smoke saturation. At the same time, the detector located 14 in. lower measured only 30 per cent light attenuation indicating extreme stratification of smoke density (Figure 4). At 2 min $30 \mathrm{sec}$, the main cabin head-high ambient temperature was $200^{\circ} \mathrm{F}$, and, at this time, no other stations had recorded a significant temperature rise. At $4 \mathrm{~min} 30 \mathrm{sec}$, the head-high temperature had reached $570^{\circ} \mathrm{F}$, while, at seat height, the indication was $150^{\circ} \mathrm{F}$. At approximately $5 \mathrm{~min} 30 \mathrm{sec}$, the head-high temperature had risen to $650^{\circ} \mathrm{F}$, while at seat height it was $200^{\circ} \mathrm{F}$. At about $7 \mathrm{~min} 40 \mathrm{sec}$, the head-high temperature had risen to $760^{\circ} \mathrm{F}$, and the seat height temperature, to $300^{\circ} \mathrm{F}$, but the cockpit temperature was still ambient. At this point, the recorder tapes indicate a flashover of the entire cabin, and within seconds the temperatures soared to the $1,700^{\circ}$ to $2,000^{\circ} \mathrm{F}$ range. The test 
was allowed to continue until the test section of the aircraft was totally destroyed, although no additional significant data was obtained.

Figures 6,7 and 8 are reproductions of all temperature data recorded during Test 1.

\section{TEST FIRE NO. 2}

The objective of Test 2 was to determine if survival time under postcrash fire conditions could be extended by using high expansion type foam to completely fill the occupied portions of the aircraft interior.

Cabin mock-up and instrumentation were identical with Test 1 . Forty gallons of fuel were placed in the port pan over the 4 in. water bottom. The additional fuel was used to provide a fire with a longer period at maximum intensity. Since the exposed surface $(3 \mathrm{ft} \times 5 \mathrm{ft})$ was identical with Test 1 , the maximum intensity of the fire, i.e., maximum heat output, was not significantly increased above the Test 1 level.

In this test, a 2,000 cfm Rockwood X-2 high expansion foam generator was installed in the cockpit, and located so that the foam would flow down the short access passageway $(6 \mathrm{ft})$ into the cabin mock-up section. Five gallons of foam liquid concentrate were located adjacent to the generator and connected to a device that metered the concentrate into the water stream at the predetermined 2 per cent rate. Water supply for the generator was a fire department pumper-tanker, connected through a 11/2-in. hose line. Water pressure was a constant 125 psi during the periods of operation. It was calculated that $45 \mathrm{sec}$ of operation would generate an amount of foam equal to $11 / 2$ times the volume of the cabin.

Wind direction was east-northeast, and wind velocity was 10 to. 12 knots.

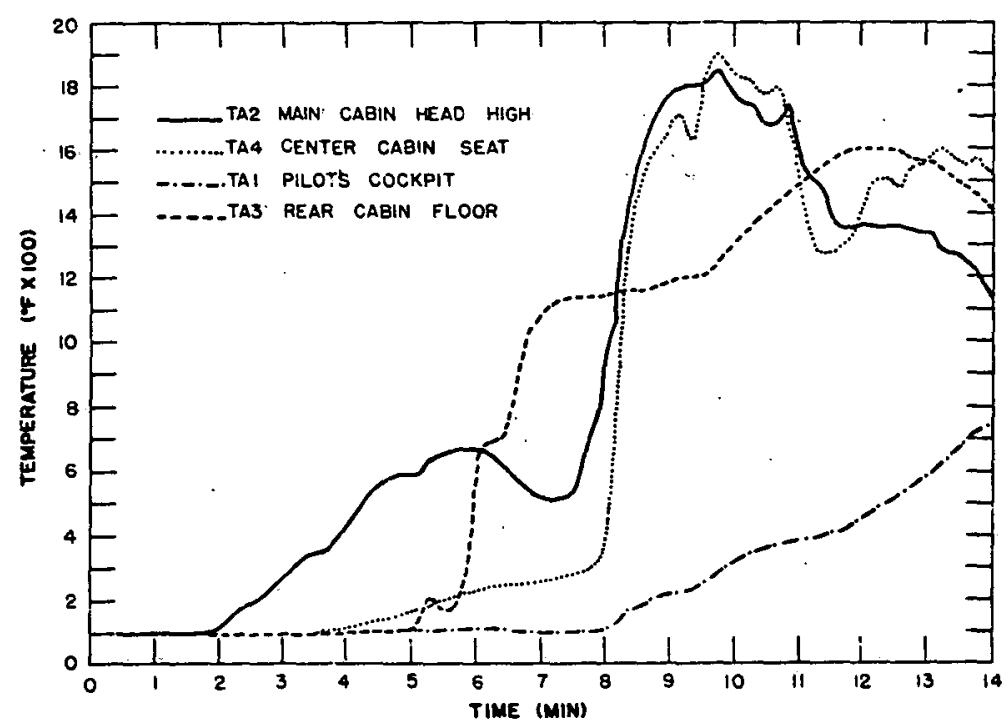

Figure.6. Temperature measurements in control aircraft, Test 1. 
Cleveland Tests

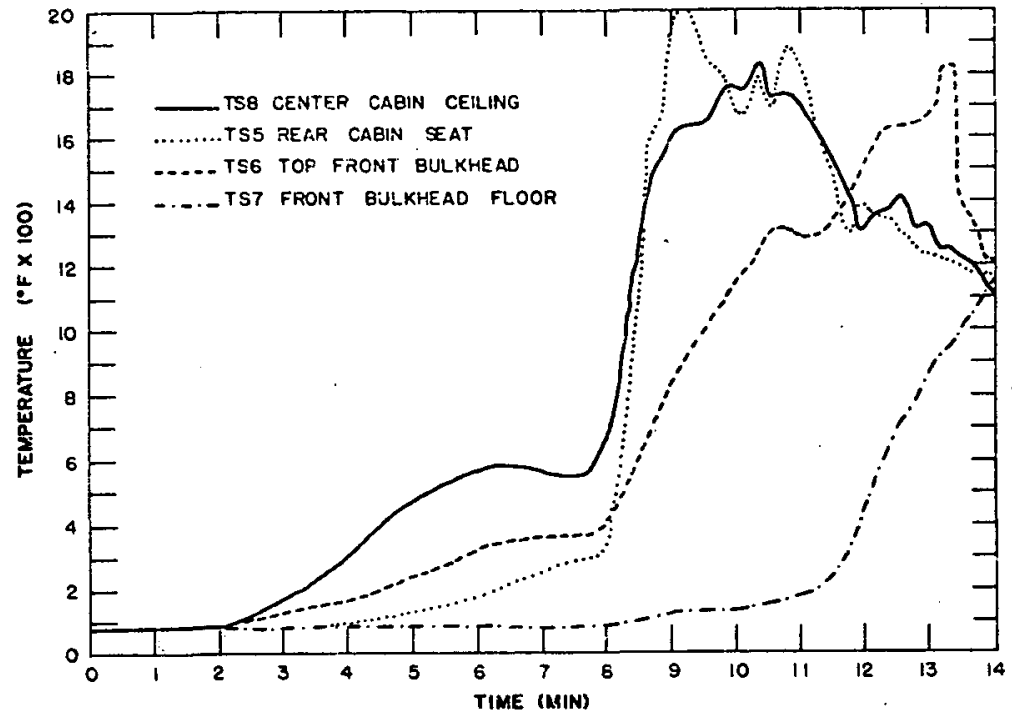

Figure 7. Temperature measurements in control aircraft, Test 1.

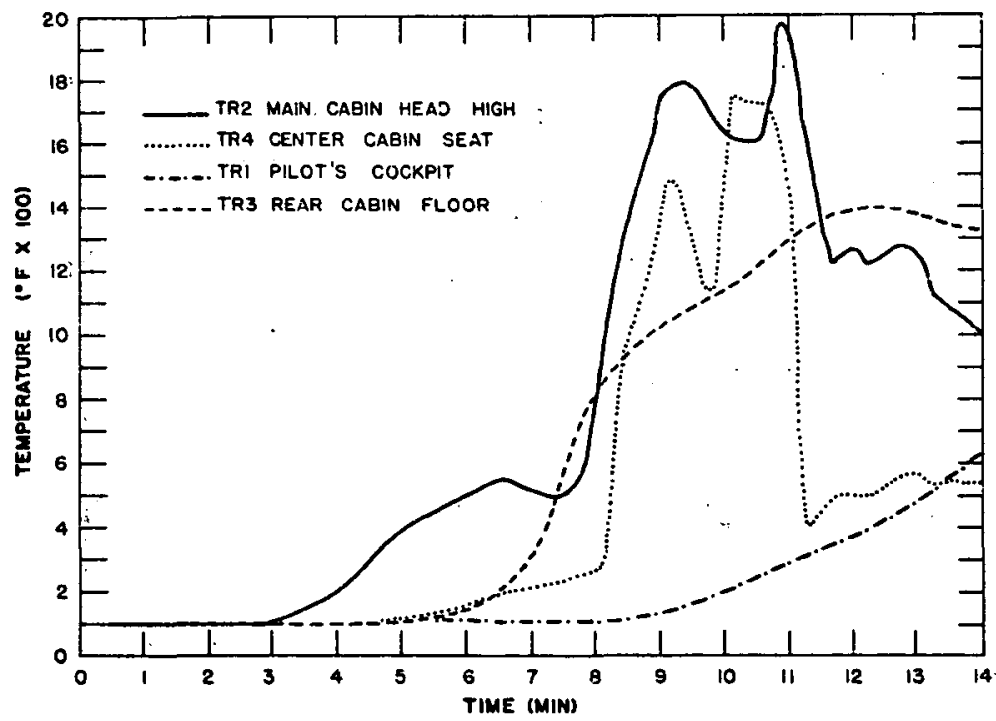

Figure 8. Temperature measurements in control aircraft, Test 1.

The initial burn-through of the fuselage skin occurred in the vacant section of the fuselage aft of the mock-up cabin, and progressed through the aft cabin bulkhead, which consisted of a melamine laminate bonded to aluminum sheet and aluminum honeycomb material. The actual time of this burn-through was not precisely detected. The first indication of smoke in the cabin occurred $1 \mathrm{~min} 15 \mathrm{sec}$ after ignition, and, at $2 \mathrm{~min}$, the smoke detector 6 in. from the ceiling indicated smoke saturation (see Figure 5). 
At the same time, the lower detector indicated 26 per cent light attenuation showing almost the same stratification as Test 1 . At 2 min 30 sec, the foam generator was started and allowed to run for a period of $45 \mathrm{sec}$ with no apparent effect. It was restarted at $3 \mathrm{~min} 20 \mathrm{sec}$ and allowed to run an additional 45 seconds. The first indication of a temperature rise was recorded at $2 \mathrm{~min}$, although this is not readily apparent in Figures 9, 10, and 11.

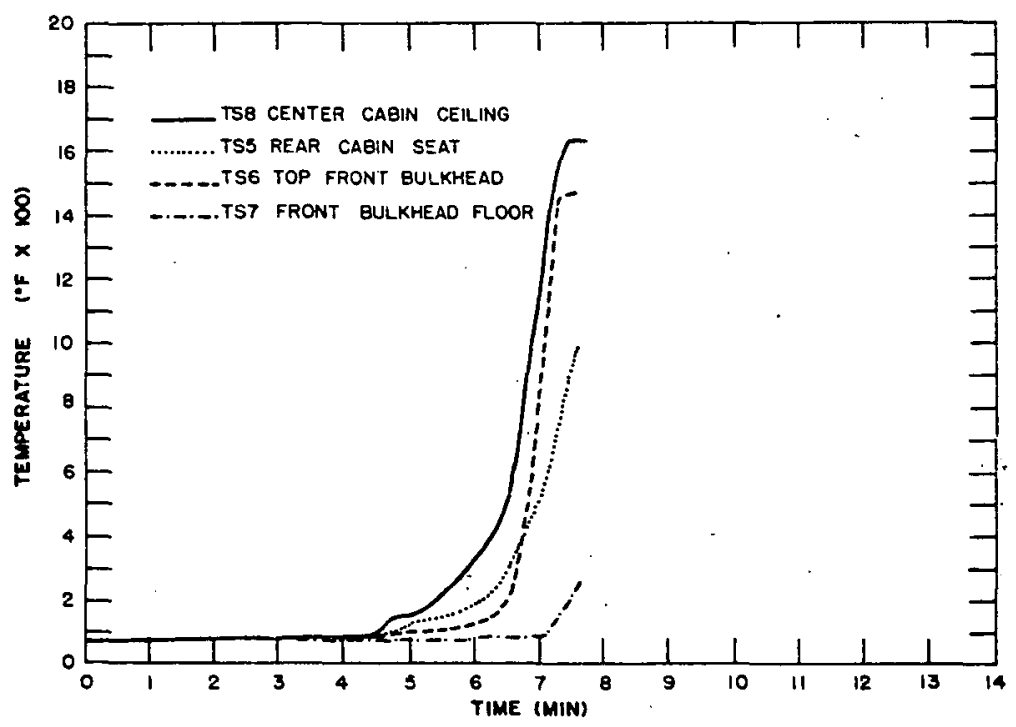

Figure 9. Temperature measurements in test aircraft, TesŁ 2.

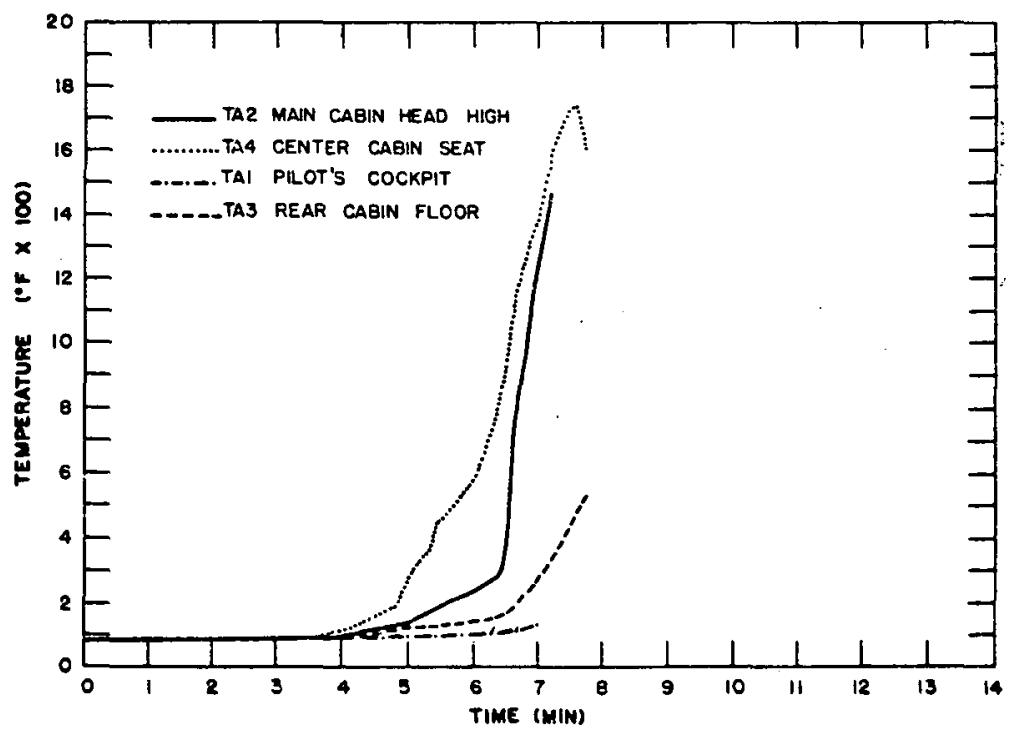

Figure 10. Temperature measurements in test aircraft, Test 2. 
At $3 \mathrm{~min}$, the main cabin head-high temperature had risen only $20^{\circ}$ above ambient. At $4 \mathrm{~min} 10 \mathrm{sec}$, the head-high temperature was $125^{\circ}$, and, at $4 \mathrm{~min} 50 \mathrm{sec}$, it reached $200^{\circ}$. The thermocouple at seat height had reached only $130^{\circ}$ after $4 \mathrm{~min} 50 \mathrm{sec}$, and it did not reach $200^{\circ}$ until $5 \mathrm{~min} 35 \mathrm{sec}$. At about $6 \mathrm{~min} 10 \mathrm{sec}$, the temperatures at various stations started rising rapidly and reached over $1,500^{\circ}$ at $7 \mathrm{~min}$, when the test was discontinued and the fire extinguished. Figures 9,10 , and 11 are reproductions of all temperature data recorded during Test 2 .

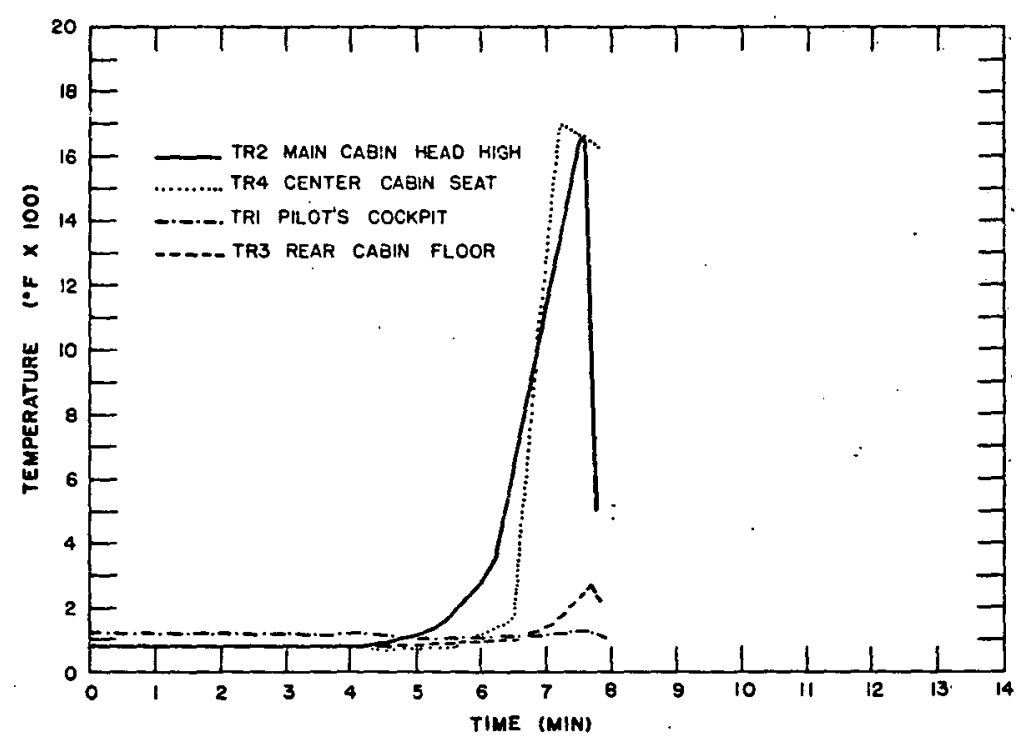

Figure 11. Temperature measurements in test aircraft, Test 2.

It was apparent from visual observation of Test 2 that, for some reason, we had not reached our objective of smoke control, even though a preliminary readout of the temperature data showed the cabin temperatures remained at or near ambient for a much longer period after burn-through than in Test 1 . In Test 2, the foam generator depended on ambient cabin air, which was heavily charged with smoke and other products of combustion/pyrolysis, for foam generation. A check was made, which elininated the possibility of mechanical failure of the foam generating equipment. The theory was advanced that some ingredient in the smoke and combustion products was "poisoning" the foam, causing an early breakdown or only partial formation.

\section{SUBSEQUENT TEST ING}

As a result of the apparent failure of the foam to perform as predicted; subsequent testing was conducted to prove or disprove the theory that products of combustion/pyrolysis "poisoned" the foam. To accomplish this test, a foam generator of the identical make and model was used, and products of combustion/pyrolysis of the various materials used in the test 
aircraft were selectively induced into the intake of the operating foam generator. The tests were conducted at the same (125 psi) pump pressure as in the aircraft test. The generator discharged into an enclosure of a known volume in order that expansion ratios could be calculated.

While the combustion products of most materials tested had a measurable effect on the expansion ratio of the foam, none were considered significant except those containing vinyl plastic. In those cases where products of combustion of vinyl plastics were ducted into the foam generator, the expansion ratio of the finished foam was so low that it could not be calculated by this test method. All the high expansion foam compounds that were currently available as well as Type 5 protein base foam were tested with the same results.

It was also deemed advisable to determine the ability of the foam to flow around and over the normal obstructions found within an aircraft cabin, i.e., seats, bulkheads, etc. For this testing, a Boeing 720 aircraft in a standard three-class passenger configuration was made available to the authors. Two X-15 Rockwood foam generators of $15,000 \mathrm{cfm}$ rated capacity were used. Each generator was connected by means of a flexible nylon duct to one of the overwing emergency exits which, in this aircraft, were located in the center cabin section. The fill of the cabin was successfully accomplished, and the foam performed as expected in flowing over and around seats and bulkheads.

\section{O N C L USIONS}

As a result of the subsequent testing of the effects of the products of combustion/pyrolysis on the expansion ratio of the high expansion foam, it is concluded that foam breakdown was the primary reason for its failure to control flame spread, temperature rise, and smoke production in the aircraft fire test. This knowledge is extremely important since all proposals known to the authors for an "on board" foam fire suppression system are predicated on using ambient cabin air for foam generation as was the case in Test 2 . This air could be heavily smoke-charged under postcrash fire conditions.

High expansion foam could be of major value in extending survival times under post-crash fire conditions. However, existing hardware for foam generation is not suitable for airborne use, and all proposals for this application have some serious drawbacks. Research and development should continue to attempt to produce effective, practical, and economical airborne units. Further development is also needed on equipment for use by ground fire fighting personnel. Hardware available today, while probably effective, is too difficult to set up and too slow to be a real value in post-crash fire where time is of the utmost importance.

For many years, the predominant thinking within the aircraft industry has been that the rapid temperature increase within the cabin under postcrash fire conditions is the controlling factor in human survivability, discounting traumatic injuries due to high impact forces. Consequently, most 
research in post-crash fire survivability has been tailored to this concept.

Analysis of the temperature data in Tests 1 and 2 , when correlated with the laboratory analysis of the products of combustion/pyrolysis, would seem to indicate that it is not necessary for temperatures to become elevated beyond survivable limits before a lethal environment can exist. The laboratory report of the analysis of the products of combustion/ pyrolysis draws the following conclusions:

"There is no doubt that the vapors resulting from the combustion. of the two aircraft contain highly toxic substances. The most obvious toxic gases are carbon monoxide, hydrogen cyanide, and ammonia. The American Conference of Governmental Industrial Hygienists lists the threshold values for these gases on a parts per million basis [for the average 8-hour per day concentration in air or a vapor,. gas, dust, or fume, to which persons may be exposed without injury to health], and, on the table below, we list the largest amount of these gases found during the burning at a particular instance in time.

ALPA-NASA-UAL Aircraft Burning Experiment

\begin{tabular}{ccc}
\hline Gas & $\begin{array}{c}\text { ACGIH Threshold } \\
\text { values }(p p m)\end{array}$ & $\begin{array}{c}\text { Largest values found } \\
\text { during experiment }(p p m)\end{array}$ \\
\hline Carbon monoxide & 100 & 180,000 \\
Ammonia & 100 & 14,960 \\
Hydrogen cyanide & 10 & 43,000 \\
Nitric oxide & 5 & 16 \\
\hline
\end{tabular}

The ACGIH threshold values given in the table represent safe limits for 8 -hour exposures; however, higher concentrations can be tolerated for shorter periods of time. - Ed.

"In addition, we know that tremendous amounts of vinyl chloride were in the atmosphere. This was confirmed by the infrared spectra of this material found in the leads to the gas sampling tubes. The ACGIH lists a threshold value of $500 \mathrm{ppm}$ for vinyl chloride. We are reasonably certain that this concentration was exceeded in the gases formed during particular instances of the burning.

"It is unfortunate that, in this examination, some of the more exotic thermal degradation products escaped detection. The literature is replete with findings of toxic materials resulting from the thermal degradation of the common plastics used in the aircraft fittings and furnishings. Some of these toxic substances referred to in the literature are styrene, benzene, and toluene.

"Consideration should also be given to the presence of large amounts of carbon dioxide. Though carbon dioxide is not particularly toxic, its presence in quantities as large as 11 per cent would indicate that the atmosphere is deficient in oxygen to the point where it will not support life."

All materials used in the mock-up cabins met or exceeded existing FAA criteria for flame resistance (Flight Safety Standard FR 453). These criteria 
are based on a small laboratory sample tested under ambient temperature conditions. The Cleveland test only added to the mounting evidence that the existing standard tests do not simulate conditions encountered in postcrash fires. The standards are now under re-evaluation and revision, and undoubtedly, more stringent flame spread requirements will be made. However, in view of the large amounts of dense, black smoke and toxic products resulting from some materials, it is felt that the new criteria should include realistic limitations on permissible smoke generation and highly toxic products of combustion and/or pyrolysis.

Acknow ledgments: The Cleveland Fire Tests were unique in many ways. There were many valuable lessons learned, which would have been lost, had it not been for the utmost cooperation of many agencies including union, management, industry, and government, both local and federal. The Air Line Pilots Association's Rescue and Fire Committee initiated this project, but only through the cooperative efforts of many was it brought to a successful conchusion.

The organizations participating actively in the tests were the Air Line Pilots Association, United Air Lines, the National Aeronautics and Space Administration, Cleveland Hopkins Airport Fire Department, Bliss-Rockwood Corporation, The Ansul Company, Duracote Corporation, E. W. Bliss Company, Crobaugh Laboratories, and the Walter Motor T'ruck Company. The assistance rendered by these organizations, without which these tests would not have been possible, is sincerely appreciated. 